\title{
Retrograde intrarenal surgery (RIRS), regular and small sized percutaneous nephrolithotomy (PCNL) in daily practice: European Association of Urology Section of Urolithiasis (EULIS) Survey
}

\author{
Stefano Paolo Zanetti ${ }^{1}$, Luca Boeri $^{1}$, Michele Catellani ${ }^{1}$, Andrea Gallioli ${ }^{1^{*}}$, Alberto Trinchieri ${ }^{2}$, \\ Kemal Sarica ${ }^{3}$, Emanuele Montanari ${ }^{4}$ \\ ${ }^{1}$ Ospedale San Paolo, Urological Department, Medical School University of Milan, Milan, Italy; \\ 2 Ospedale Alessandro Manzoni Lecco, Urological Department, Lecco, Italy; \\ ${ }^{3}$ Dr. Lutfi Kirdar Training and Research Hospital, Urological Department, Semsi Denizer Cad. E-5 Karayolu Cevizli Mevkii, 34890, \\ Kartal/Istanbul, Turkey; \\ ${ }^{4}$ Fondazione IRCCS Ca' Granda Ospedale Maggiore Policlinico, Urological Department, Medical School University of Milan, Milan, Italy.
}

\begin{abstract}
Summary Objective: A wide selection of both anterograde and retrograde mini-invasive procedures exist for stones' treatment. The 2016 European Association of Urology (EAU) guidelines still don't univocally define a best option. Our purpose is to give an overview on some European Stone Centers' customs and to compare real life clinical practice with statements of opinion leaders and Guidelines.

Materials and Methods: In 2015 we performed a survey in 3 step about the spread of retrograde intrarenal surgery (RIRS) and percutaneous nephrolithotomy (PCNL) techniques among EAU Section of Urolithiasis (EULIS) members. The 1st and 2nd steps dealt with the definition of EULIS urologist and department by collecting personal opinions about the endoscopic techniques. The third step was about clinical results. This paper presents data from the first two steps.

Results: Ninety-one people answered. Out of them, $80 \%$ are European and $42 \%$ work in Centres fully dedicated to stone treatment. In particular, $50 \%$ of responders perform more than 80 RIRS/year, 25\% more than 80 PCNL/year, $48 \%$ more than 100 extracorporeal shock wave lithotripsy (SWL)/year. RIRS is mainly used to treat stones $<2 \mathrm{~cm}$ both as primary treatment and after SWL failure. $73 \%$ don't perform routine pre-stenting and $66 \%$ ordinarily use a ureteral sheath. Hospital stay for RIRS is $24 \mathrm{~h}$ for $70 \%$ of responders. Regular PCNL is performed by $87 \%$ of the responders, MiniPCNL by $58 \%$, Ultra-MiniPCNL by $23 \%$ and MicroPCNL by $28 \%$. Pneumatic balloon dilation is the favourite dilation technique (49\%). 37\% of responders perform PCNL always in the supine position, $21 \%$ always in the prone one. Almost all the responders agree about using Mini, Ultra-Mini and MicroPCNL for 1-2 cm stones.

Approximately $50 \%$ also use MiniPCNL for stones $>2 \mathrm{~cm}$. Conclusion: our survey confirms the great heterogeneity existing in stones' treatment techniques in daily practice.
\end{abstract}

KEY WORDS: Kidney Calculi/surgery; Nephrolithotomy; Percutaneous; Retrograde intrarenal surgery; PCNL; RIRS.

Submitted 12 July 2016; Accepted 19 August 2016

\section{INTRODUCTION}

Urolithiasis management has changed over the past few decades due to the development of new mini-invasive instruments and techniques. The possibility to extract a stone through aa percutaneous access under fluoroscopic control was given by Johanson and Fernström in 1976 (1). Between 1981 and 1984 P. Alken, J.A.E. Wickham and J. Segura described endoscopic percutaneous nephrolithotomy (2-5) and Perez Castro in 1980 proposed and promoted rigid ureterorenoscopy in the stone treatment (6).

Since then, both the anterograde and retrograde techniques were perfected and miniaturized and nowadays we have a wide selection of procedures focused to the treatment of renal stones. In 1998 Mini PCNL was mentioned for the first time in order to reduce the invasiveness of the percutaneous technique (7); in 2011 Mahesh Desai performed the first Micro PCNL with a 4.8 Charrier (Ch) all seeing needle (8) and in 2013 Janak Desai described the Ultra-Mini PCNL (UMP) with a 11$13 \mathrm{Ch}$ access diameter (9).

2016 European Association of Urology (EAU) Guidelines contemplate all these techniques but still don't give a clear indication in order to choose among the "small sized PCNL" the right one to treat the patient: in fact smaller instruments present some limitations in the choice of lithotripsy instruments and in clearing fragments, require a longer operation time, increase intrarenal pelvic pressure while their main advantage, "id est" less bleeding complications, needs to be confirmed. Moreover, 2016 EAU Guidelines address PCNL as the first line treatment in kidney stones $>2 \mathrm{~cm}$ while they do not univocally define the best treatment for calculi between 1 and $2 \mathrm{~cm}$, leaving the choice to the physician (10). Many studies in literature make comparisons among the different techniques and try to suggest how to act in different situations but still many differences exist, according to single centre's experiences and protocols, in terms of surgical indications and intra-technique applications. The 
aim of the study is to give an overview on the uses and practices in some of the main European Stone Centers and on their indications for stones' treatment. Secondary objective is to compare the real life clinical practice with the indications and statements reported by opinion leaders and Guidelines.

\section{MATERIAL AND METHODS}

We performed a survey approved by the EAU Section of Urolithiasis (EULIS) board in Cape Town in December 2014 about the spread of RIRS and regular and small sized PCNL among physicians who attended Copenhagen EULIS meeting in 2013. The project was accomplished through the Survey Monkey online platform with a questionnaire in English in three steps and took place from February to May 2015.

An introductory email was sent at the beginning with description and the aim of the survey and with the Survey Monkey site linked. Participation was voluntary, without honorarium.

The first step dealt with the definition of EULIS urologist and department and the second step aimed to define personal opinions about RIRS and PCNL. From the data we disposed of at the end of the first two steps, we tried to delineate EULIS centres' uses, practices and profiles in terms of instruments' availability and techniques performed for stone treatment. Moreover we collected opinions about efficacy and usefulness of the spreading small sized PCNL techniques. In the third step responders were asked to share the clinical results of the last 5 cases of each technique in study with at least one month follow-up. In this article we will describe and analyze the data resulting from the first two steps.

\section{RESULTS}

We sent the first and second step questionnaires to 360 people and the percentage of responders was 24\% (88 responders). Seventy-eight physicians agreed to receive the third step questionnaire and the $38 \%$ out of them (30 responders) shared their data.

\section{EULIS Physician and Department}

$96 \%$ of EULIS members are urologists and $80 \%$ are European, Table 1.

\section{Table 1.}

Distribution of responders for country of origin.

\begin{tabular}{|lc|}
\hline Country & Responders, No. (\%) \\
\hline Italy & $14(15,9)$ \\
\hline Spain & $12(13,6)$ \\
\hline Denmark, Germany & $10(11,4)$ \\
\hline Greece & 8 each $(9,2$ each) \\
\hline Japan, Portugal, Turkey & $4(4,6)$ \\
\hline Bulgaria, France, India & 3 each $(3,4$ each) \\
\hline Australia, Austria, China, Dubai, Iraq, Lithuania, & 2 each $(2,4$ each) \\
Morocco, Netherlands, Norway, Pakistan, Qatar, & 1 each $(1,1$ each) \\
\hline Serbia, Sweden, Switzerland, Thailand, Uzbekistan & $1(1,1)$ \\
\hline Unknown & \\
\hline
\end{tabular}

$47 \%$ of responders work in academic clinics, $44 \%$ in public hospitals and $9 \%$ in private ones.

The distribution of the sample by age is fairly even in age groups from 35 to 65 years old, while a less represented group of responders (14\%, 12 out of 88 ) is younger than 35.

$43 \%$ (38 out of 88 ) of responders work in a stone centre dedicating all its activity to stone treatment.

$92 \%$ of responders work in Centres owning a laser dedicated to lithotripsy and $75 \%$ of them in centres owning an extracorporeal lithotripter.

Three responders out of 88 (3.41\%) do not have any flexible ureterorenoscope in their armamentarium, while 39\% of them have 2 or 3 and $42 \%$ have more than 4 .

$50 \%$ of responders work in departments performing more than 80 RIRS/year while $25 \%$ of them in departments performing more than $80 \mathrm{PCNL} /$ year, the most represented group (42\%) performing 20-60 PCNL/year. 30\% of the sample work in Departments performing more than 200 extracorporeal shock wave lithotripsy (SWL)/year and 18\% in departments performing 100-200 SWLyear.

\section{Opinions about endoscopic techniques}

\section{RIRS}

Indications to RIRS, according to responders' experience, are resumed in Table 2.

A double $\mathrm{J}$ stent is preoperatively placed in less than $1 / 3$ of the cases by $73 \%$ of the EULIS urologists and $66 \%$ use an ureteral access sheath in more than $2 / 3$ of RIRS.

$42 \%$ of responders regularly obtain an informed consent for PCNL before a RIRS and conversion rate from RIRS to PCNL is lower than $2 \%$ for $68 \%$ of responders.

The average hospital stay for RIRS is $24 \mathrm{~h}$ for $70 \%$ of responders, $48 \mathrm{~h}$ for $22 \%$ and more than 2 days for $8 \%$.

PCNLS

The spread of the different PCNL techniques is summarized in Table 3.

\section{Table 2.}

Which are your standard indications for RIRS? (More than one option allowed; total of 86 responders to this question).

\begin{tabular}{|lc|}
\hline Options & Responders, No. (\%) \\
\hline Stones $<1 \mathrm{~cm}$ (primary treatment) & $39(45)$ \\
\hline Stones $<1 \mathrm{~cm}$ (after SWL failure) & $64(74)$ \\
\hline Stones 1-2 cm (primary treatment) & $55(64)$ \\
\hline Stones 1-2 cm (after SWL failure) & $54(63)$ \\
\hline Stones $>2 \mathrm{~cm}$ (primary treatment) & $14(16)$ \\
\hline Stones $>2 \mathrm{~cm}$ (after SWL failure) & $8(9)$ \\
\hline
\end{tabular}

\section{Table 3.}

Which size of PCNL access do you perform? (More than one option allowed; total of 86 responders to this question).

\begin{tabular}{|lc|}
\hline Techniques & Responders, No. (\%) \\
\hline Regular PCNL & $75(87)$ \\
\hline Mini PCNL & $50(58)$ \\
\hline Ultra-Mini PCNL & $20(23)$ \\
\hline Micro PCNL & $24(28)$ \\
\hline
\end{tabular}




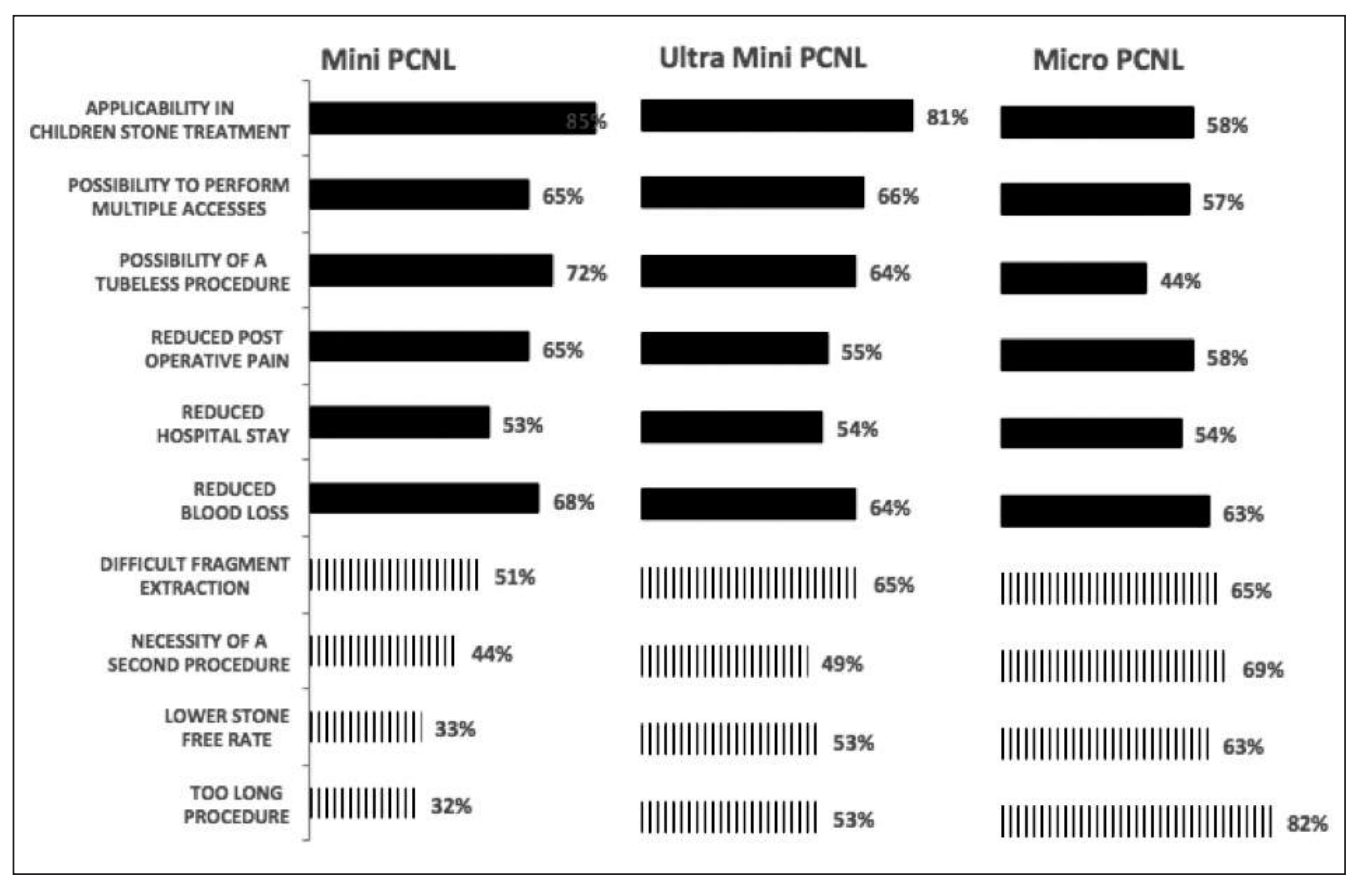

Figure 1.

Advantages and disadvantages of small sized PCNL techniques: responders were asked to score every proposed advantage (black bars) and disadvantage (dashed bars) for all the techniques. Percentages in the graphics are the proportions of responders considering the proposed item as a real advantage or disadvantage.

The perception of advantages in Mini PCNL overwhelms the perception of disadvantages. This tendency is reduced for UMP and inverted for Micro PCNL, for which disadvantages are considered greater than advantages.

Technique skills

Pneumatic balloon dilation is the favourite dilation technique for $49 \%$ of the surgeons, followed by the Alken progressive technique (29\%), the Amplatz progressive technique (16\%) and the Amplatz one shot technique (6\%).

$37 \%$ of responders always perform PCNL with the patient in any supine position, while $21 \%$ always perform the procedure with the patient in the prone position.

$36 \%$ of responders also treat children by PCNL in their department.

Small size PCNLs

$58 \%$ of the interviewed urologists perform small sized PCNL $(<20 \mathrm{ch}), 88 \%$ of the others would be interested in, but they do not have the equipment. This interest is stronger regarding UMP than Micro PCNL (respectively $75 \%$ and $61 \%$ of the respondents who don't perform these techniques would be interested in).

Table 4.

What are your indications to small sized PCNL techniques?

\begin{tabular}{|lccc|}
\hline & $\begin{array}{c}\text { Mini PCNL, } \\
\text { Responders No. (\%) } \\
\text { (84 responders } \\
\text { to this question) }\end{array}$ & $\begin{array}{c}\text { Ultra-Mini PCNL, } \\
\text { Responders No. (\%) } \\
\text { (83 responders } \\
\text { to this question) }\end{array}$ & $\begin{array}{c}\text { Mesponders No. (\%) } \\
\text { (83 responders } \\
\text { to this question) }\end{array}$ \\
\hline $1-2 \mathrm{~cm}$ stones & $71(85)$ & $83(100)$ & $82(99)$ \\
\hline$>2 \mathrm{~cm}$ stones & $44(52)$ & $7(8)$ & $3(4)$ \\
\hline
\end{tabular}

Table 5.

Do you consider small sized PCNLs and RIRS alternative?

\begin{tabular}{|cccc|}
\hline & $\begin{array}{c}\text { Mini PCNL, } \\
\text { Responders No. (\%) } \\
\text { (84 responders } \\
\text { to this question) }\end{array}$ & $\begin{array}{c}\text { Ultra-Mini PCNL, } \\
\text { Responders No. (\%) } \\
\text { (83 responders } \\
\text { to this question) }\end{array}$ & $\begin{array}{c}\text { Micro PCNL, } \\
\text { Responders No. (\%) } \\
\text { (83 responders } \\
\text { to this question) }\end{array}$ \\
\hline Yes & $38(45)$ & $41(49)$ & $27(33)$ \\
\hline
\end{tabular}

The $79 \%$ of the responders believe it's important, in terms of invasiveness, to move from Regular to Mini PCNL, 54\% from Mini PCNL to UMP and 45\% from UMP to Micro PCNL. Indications to small sized PCNLs and opinions about their relation with RIRS are resumed in Tables 4 and 5 respectively.

The responders' favourite stone-breaking energy in Mini PCNL is laser, used by $90 \%$ followed by ballistic energy used by $32 \%$.

The perceptions of advantages and disadvantages of small sized PCNL techniques compared to Regular PCNL are summarized in Figure 1.

\section{Discussion}

This paper presents the first Survey inside EULIS group. Although EULIS is a European Society, 19,1\% of responders come from extra-European countries (Table 1) confirming the interest for the European scientific associations.

\section{RIRS}

Considering the Departments' armamentarium almost all the Centres own a laser dedicated to stone treatment and more than one flexible ureteroscope, demonstrating the actual large spread of the retrograde technique. RIRS diffusion is confirmed by the high proportions of centres performing more than 80 procedures per year (50\%) that doubles the one of the centres performing the same number of PCNLs. Anyway SWL appears to be the most popular technique for stone treatment: in almost $50 \%$ of the centres more than 100 shock-wave treatments per year are performed. It probably suggests that the most of the Stone Experts use SWL as first approach for stones and this hypothesis is confirmed by the large proportions of responders considering SWL as primary treatment for stones $<2$ $\mathrm{cm}$ (Table 2). Less than 20\% of the responders consider RIRS a suitable technique for stones larger than $2 \mathrm{~cm}$ according to EAU Guidelines that consider PCNL the treat- 
ment of choice. Many studies in literature report high stone free rates with low morbidity in RIRS performed for stones larger than $2 \mathrm{~cm}$ (11-12) but our survey shows that the majority of EULIS departments don't apply these statements in the daily clinical practice.

The majority of responders preoperatively place a ureteral double J stent only in a small amount of cases according to expert opinions which don't recommend routine pre-stenting unless necessary in order to insert a ureteral access sheath, when the force needed to insert the device in a prior procedure seems unreasonable (13).

The ureteral access sheath is largely used by the EULIS urologists performing RIRS, as extensively suggested in literature (14) in order to reduce intrapelvic pressure.

Even if a discrete number of Centres routinely obtain an informed consent for PCNL before a RIRS, the reported conversion rate from RIRS to PCNL is very low for the majority of the Departments.

Hospital stay for RIRS is $24 \mathrm{~h}$ for the greatest part of the departments and this datum confirms what pointed out by De et al (15). In their review and meta-analysis they observed, in the majority of the studies analysed, a mean hospital stay for RIRS between $24 \mathrm{~h}$ and $48 \mathrm{~h}$ and an overall shorter length of stay for RIRS than for PCNL.

\section{PCNLS}

The great majority of the urologists perform Regular PCNL while we observed a smaller diffusion of the PCNLs procedures by reducing the percutaneous tract size (Table 3). As a matter of facts only a few more than $50 \%$ of our responders perform small size PCNLs even if almost all the other would be interested in, but they do not have the equipment. This interest appears stronger regarding Mini PCNL than UMP and Micro PCNL, for which the importance in terms of invasiveness is considered progressively lower by reducing the percutaneous access diameter.

About intraoperative technical manoeuvres, in contrast to the tendency of EULIS people, who apparently do not appreciate the Amplatz one shot dilation technique, the meta-analysis published by Dehong et al. (16) shows that the one shot technique is safe and effective in all the patients. According to the same study the balloon dilation, the preferred technique among EULIS group, is safer and more effective than the Amplatz progressive dilation and the Alken's metal telescopic dilation in patients without previous open renal surgery, while the effectiveness and safety of balloon dilation are lower than the Amplatz progressive and the metal telescopic dilation ones in patients with densely scarred tissue.

Yamaguchi et al, in their study on 5537 patients conducted of behalf of the Clinical Research Office of the Endourological Society (CROES), report a significantly higher bleeding rate in patients undergoing balloon dilation compared with telescopic/serial dilation (9.4\% vs $6.7 \%$; $\mathrm{P}<0.0001)$. Balloon dilation was also associated with significantly more transfusions $(\mathrm{P}=0.001)$ and greater drops in haematocrit level $(\mathrm{P}<0.0001)$ than telescopic/serial dilation, as well as significantly longer median operating times $(\mathrm{P}<0.0001)(17)$. Regarding patient's position during PCNL, EULIS physicians' opinions are split, someone always performing the procedure with the patient in the prone position, someone always with the patient in the supine one and some- one alternating. Liu et al. review and meta-analysis (18) shows that PCNL in the supine position is as safe and efficacious as the conventional prone position and there's not an overwhelming evidence indicating which one is better. As concluded by Baard et al., considering the advantages of supine position in the morbidly obese, patients with skeletal deformities and patients with severe cardiorespiratory morbidity, it is important to have experience with several positions. The decision on position should be made on patient's characteristics and surgeon's preference and experience (19).

We found in the literature only few articles defining precise indications to the different percutaneous techniques according to stone size. In their first paper on UMP, J. Desai and $R$. Solanki conclude that their technique is safe and effective for stones up to $2 \mathrm{~cm}$ (9). Ganpule et al., in their study on factors predicting outcomes of Micro PCNL, assert that this technique appears to be a promising treatment method for solitary renal stones with volumes $<1000$ $\mathrm{mm} 3$ and with low density (Hounsfield Units), regardless of stone location (20). Our responders agree about treating 1$2 \mathrm{~cm}$ stones with Mini, Ultra-Mini and Micro PCNL. Approximately the half of them also use Mini PCNL for stones larger than $2 \mathrm{~cm}$, while only a very small proportion of urologists consider Ultra-Mini and Micro PCNL suitable techniques for this type of stones.

De et al. review (15) reports that RIRS can provide higher stone free rates with equal complication rate when compared with minimally invasive percutaneous procedures, including Mini and Micro PCNL. Nevertheless, almost the half of our responders consider Mini and Ultra-Mini PCNL alternative to RIRS in stones treatment, while only a smaller proportion of urologists thinks the same regarding Micro PCNL which is probably mainly used in highly selected cases.

For what concerns responders' perception of small size PCNL's advantages and disadvantages summarized in Figure 1, Mini PCNL appears to be EULIS urologists' favourite technique among small size PCNLs.

\section{Conclusions}

Our Survey confirms the great heterogeneity existing in the treatment of urolithiasis both in the choice of the different endoscopic techniques and in the surgical steps of the procedures. Moreover the real-life clinical practice is not always in line with the literature.

In particular, while RIRS technique seems to be quite well standardized, the debate appears to be open on PCNL techniques, in particular regarding the indications to the different access tract sizes. The impression is that Micro and Ultra-Mini PCNL are considered suitable techniques for stones up to $2 \mathrm{~cm}$, while Mini PCNL could be used in larger stones too, but to assess evidence based indications further randomized prospective studies should be performed.

\section{Acknowledgments are posted on www.aiua.it}

\section{REFERENCES}

1. Fernström I, Johansson B. Percutaneous pyelolithotomy. A new extraction technique. Scand J Urol Nephrol. 1976; 10:257. 
2. Alken P, Hutschenreiter G, Günther R, Marberger M. Percutaneous stone manipulation. J Urol. 1981; 125:463.

3. Wickham JEA, Kellet MJ. Percutaneous nephrolithotomy. BMJ 1981; 283:1571.

4. Segura JW, Patterson DE, LeRoy AJ, et al. Percutaneous removal of kidney stones. Preliminary report. Mayo Clin Proc. 1982; 57:615.

5. Patel S, Nakada S. The Modern history and evolution of percutaneous nephrolithotomy. J Endourol. 2015; 29:153.

6. Perez Castro E, Puigbert Gorro A, Cifuentes Deatte L. La ureterorrenoscopia transuretral. Un actual proceder urologico. Arch Esp Urol. 1980; 23:5.

7. Jackman SV, Docimo SG, Cadeddu JA, et al. The "mini-perc" technique: a less invasive alternative to percutaneous nephrolithotomy. World J Urol. 1998; 16:371.

8. Bader MJ, Gratzke C, Seitz M, et al. The "all-seeing needle": initial results of an optical puncture system confirming access in percutaneous nephrolithotomy. Eur Urol. 2011; 59:1054.

9. Desai J, Solanki R. Ultra-mini percutaneous nephrolithotomy (UMP): one more armamentarium. BJU Int. 2013; 7:1046.

10. Türk C. (2016) Guidelines on urolithiasis. European Association of Urology. https://uroweb.org/guideline/urolithiasis/\#note_1-6. Accessed 15 April 2016.

11. Aboumarzouk OM, Monga M, Kata SG, et al. Flexible ureteroscopy and laser lithotripsy for stones $>2 \mathrm{~cm}$ : a systematic review and meta-analysis. J Endourol. 2012; 26:1257.

12. Breda A, Angerri O. Retrograde intrarenal surgery for kidney stones larger than $2.5 \mathrm{~cm}$. Curr Opin Urol. 2014; 24:179.
13. Traxer O, Thomas A. Prospective evaluation and classification of ureteral wall injuries resulting from insertion of a ureteral access sheath during retrograde intrarenal surgery. J Urol. 2013; 189:580.

14. Auge BK, Pietrow PK, Lallas CD, et al. Ureteral access sheath provides protection against elevated renal pressures during routine flexible ureteroscopic stone manipulation. J Endourol. 2004; 18:33.

15. De S, Autorino R, Kim FJ, et al. Percutaneous nephrolithotomy versus retrograde internal surgery: a systematic review and meta-analysis. Eur Urol. 2015; 67:125.

16. Dehong C, Liangren L, Huawei L, Qiang W. A comparison among four tract dilation methods of percutaneous nephrolithotomy a systematic review and meta-analysis. Urolithiasis. 2014; 41:523.

17. Yamaguchi A, Skolarikos A, Buchholz NP, et al. Clinical Research Office Of The Endourological Society Percutaneous Nephrolithotomy Study Group. Operating times and bleeding complications in percutaneous nephrolithotomy: a comparison of tract dilation methods in 5,537 patients in the Clinical Research Office of the Endourological Society Percutaneous Nephrolithotomy Global Study. J Endourol. 2011; 25:933.

18. Liu L, Zheng S, Xu Y, Wei Q. Systematic review and meta-analysis of percutaneous nephrolithotomy for patients in the supine versus prone position. J Endourol. 2010; 24:1941.

19. Baard J, Kamphuis GM, Westendarp M, de la Rosette JJ. How well tolerated is supine percutaneous nephrolithotomy? Curr Opin Urol. 2014; $24: 184$.

20. Ganpule A, Chhabra JS, Kore V, et al. Factors predicting outcomes of micropercutaneous nephrolithotomy: results from a large single-centre experience. BJU Int. 2016; 117:478.

\section{Correspondence}

Stefano P. Zanetti, MD

stefano.p.zanetti@gmail.com

Luca Boeri, MD

dr.lucaboeri@gmail.com

Michele Catellani, MD

michele.catellani@gmail.com

Andrea Gallioli, MD (Corresponding Author)

andrea.gallioli@gmail.com

Ospedale San Paolo, Urological Department, Medical School University of Milan

Via Antonio di Rudini 8, 20146 - Milan, Italy

Alberto Trinchieri, MD

a.trinchieri@ospedale.lecco.it

Ospedale Alessandro Manzoni Lecco, Urological Department

Via dell'Eremo 9/11, 23900 - Lecco, Italy

Kemal Sarica, MD

saricakemal@gmail.com

Dr. Lutfi Kirdar Training and Research Hospital, Urological Department

Semsi Denizer Cad. E-5 Karayolu Cevizli Mevkii, 34890, Kartal/Istanbul, Turkey

Emanuele Montanari, MD

emanuele.montanari@unimi.it

Fondazione IRCCS Ca' Granda Ospedale Maggiore Policlinico, Urological Department,

Medical School University of Milan, Via della Commenda 15, 20122 - Milan, Italy 